\title{
A Simulation-Based Comprehensive Analysis for Traffic Efficiency and Spatial Distribution of Risks in Short Weaving Area of Municipal Interchange
}

\author{
Xiaofei Wang (D), Zhenzhong Ding (D), Kai Guo $(\mathbb{D}$, and Yongjie Lin (D) \\ School of Civil Engineering and Transportation, South China University of Technology, Guangzhou 510641, China \\ Correspondence should be addressed to Yongjie Lin; linyjscut@scut.edu.cn
}

Received 12 March 2021; Accepted 5 May 2021; Published 19 May 2021

Academic Editor: Xinqiang Chen

Copyright ( 2021 Xiaofei Wang et al. This is an open access article distributed under the Creative Commons Attribution License, which permits unrestricted use, distribution, and reproduction in any medium, provided the original work is properly cited.

\begin{abstract}
The weaving area is an important junction that affects the efficiency and traffic safety at the municipal interchanges. To explore the factors affecting traffic efficiency and the spatial distribution characteristics of traffic risks in the weaving areas of municipal interchanges, this study employed a microscopic traffic software of Vissim to construct a simulation model of weaving areas and evaluate the impact of road and traffic design parameters in the short weaving on traffic efficiency and risks, which includes ramp delay, mainline through lane (TL) traffic delay, average ramp speed, TL average speed, and collision rate. Through variance analysis via a large number of simulation scenarios, the weaving length is identified as the most important factor affecting traffic efficiency and risks in the short weaving area. Subsequently, three different types of weaving lengths with $350 \mathrm{~m}, 450 \mathrm{~m}$, and $550 \mathrm{~m}$ were set to conduct the sensitivity analysis based on four performance indexes of mean acceleration and deceleration, acceleration range, deceleration range, and speed standard deviation as the representative variables of spatial risk distribution. The simulation results illustrate that a shorter weaving length has a significant influence on risk distribution, especially the highest risk probability at the positions after three-quarters of the inner and outer lanes in the short weaving area at the municipal interchange. Finally, this study verified the traffic risk reduction method of having traffic safety facilities and traffic organization at the complex interchange with double-entry and single-exit weaving areas in the city of Guangzhou, China. The research proposed a method to analyze the influence of the design parameters in the short weaving area on traffic efficiency and safety and provided a reference for the risk spatial distribution analysis and improvement in the short weaving area.
\end{abstract}

\section{Introduction}

At municipal interchanges, merge and diverge weaving areas are usually dense and concentrated where one of the most important purposes is to protect ecological land and save land capital. However, around the short weaving areas of this kind of municipal interchanges, the frequent vehicle lanechanging affects traffic efficiency and safety, leading to traffic flow disorder and increased risk of traffic accidents. The short weaving area has gradually become an accident-prone one with concentrated risk at municipal interchanges. Nowadays, many researchers are mainly focused on the impact of traffic characteristics on the risk and identification of hazardous segments in weaving areas. However, few researchers reported the spatial distribution characteristics of traffic risks in the short weaving areas of municipal interchanges.

Therefore, this study will analyze the distribution characteristics of traffic efficiency and risks around the short weaving areas of the typical municipal interchange with three main lanes and an auxiliary lane, double-ramp entry, and single exit. Firstly, the popular traffic microsimulation software of Vissim is used to research traffic efficiency and risk at the short weaving areas. Taking four parameters (i.e., weaving area length, traffic volume, interweaving traffic ratio, and interweaving ratio) as design variables, this study analyzes their respective influences on traffic efficiency and risk. Also, the sequence of five influencing factors (i.e., mean acceleration, mean deceleration, acceleration range, deceleration range, and speed standard deviation) is obtained by 
variance analysis. On this basis, the spatial distribution characteristics of risk in weaving areas are further recognized under three weaving lengths: 350, 450, and $550 \mathrm{~m}$. Furthermore, the corresponding traffic optimization method scheme of traffic safety facilities and traffic organization is put forward to improve traffic safety in the short weaving areas of municipal interchanges.

\section{Literature Review}

If two adjacent ramps are close to each other on an expressway, the motorized vehicles need to merge or diverge on a single ramp, which will have an impact on the vehicles in the TL and adjacent ramps. Therefore, these two ramps and the weaving area between them should be considered as a whole.

There have been many research studies in the design of short weaving areas on highways. Chen [1] used the Traffic Software Integrated System (TSIS) to build a model for the combination of ramps. $\mathrm{Li}$ [2] discussed a conventional arrangement method of entrances and exits, the layout method of auxiliary lanes, and the advantages and disadvantages of the method of scissors arrangement in the elevated expressway. Huang and Chen [3] calculated weaving length with a calculation method of traffic capacity in the weaving area, analyzing the running characteristics of vehicles. The minimum distance required for acceleration and deceleration of vehicles was researched from the principles of dynamics. Thus, the calculation model of the minimum distance between connecting parts of a ramp was constructed. Pan [4] put forward the treatment plan for traffic and civil engineering when researching the design of entrances and exits in new expressway projects. These research studies provided a reference for the parameter selection of the short weaving area.

So far, HCM 2010 [5] and China's norms [6] are not enough to analyze the efficiency and safety of short weaving areas. HCM2010 has collected mature research results on the traffic flow operation state, operation influencing factors, and traffic capacity analysis in the weaving area. However, there are few studies on its application in the field of traffic safety in the weaving area because it often only considers the limited factors such as ramp form and traffic volume or makes a relatively rough analysis of the weaving area as part of the overall safety evaluation model of the interchange. In contrast, the analysis of the weaving area in China's norms still uses speed consistency to evaluate safety.

Currently, some researchers studying weaving area safety and traffic efficiency mainly concentrate on the impact of traffic characteristics on the weaving area risk and traffic efficiency characteristics. Collecting freeway crash records, geometric design data, and weather data, Wang et al. [7] proposed a multistage Bayesian logistic regression model for collision in the freeway weaving segment, using the Microwave Vehicle Detection System (MVDS). Abdel-Aty and Wang [8] tested several variable-speed-limit strategies after calibration and verification in microsimulation. Wang et al. [9] established a lane-changing conflict model and used a statistical analysis method to study the vehicle running characteristics and lane-changing process in the weaving area of expressways, classifying lane-change conflicts into four different levels. Li et al. [10] determined the optimal weaving scheme under different combination designs of lanes in weaving areas by taking the traffic conflict rate as the safety evaluation index. Yuan et al. [11] discussed the impact of weaving length, traffic conditions, and drivers' characteristics on drivers' behavior of forced lane changing from the perspective of safety using a driving simulator. Hao et al. [12] explored the proposed models of the vehicle lanechanging process of highway weaving areas from the driver's level and provided the safety for CAV vehicle to change lane recognition in the weaving area. Kim and Park [13] studied the collision-rate distribution in highway weaving segments and buffer-separated high-occupancy lanes. Cai et al. [14] comprehensively studied the safety impact of different lengths after each lane change on the weaving segments of the general lane close to entrances and exits using VISSIM microsimulation and a driving simulator. Dong et al. [15] used a mixed logit model to examine the difference of SV and MV accident probability and found traffic, road, surface characteristics are the main influencing factors of SV and MV accident possibility. Selecting a representative ramp exit of an expressway in Changchun, China, Liang et al. [16] analyzed characteristics of traffic conflicts, traffic flow, and traffic density and built a model to study the relationship between the number of traffic conflicts and traffic flow and density.

At the same time, some other research studies have reported the dangerous segment identification of the short weaving area and the overall optimization method for the traffic efficiency and safety of the short weaving area. Lord and Bonneson [17] found that there were more crashes on crossroad off-ramps than crossroad on-ramps by a ratio of 1.5 , and non-free-flow ramps had twice as many crashes as other ramp types. Kusuma et al. [18, 19] analyzed the two weaving segments between junctions 41 and 43 of the M1 motorway, and results showed that approximately $1 / 4$ of the interweaving behaviors occurred $50-100 \mathrm{~m}$ before the junction. Chi and $\mathrm{He}[20]$ took the comprehensive risk index of traffic conflict as an evaluation index and determined the overall evaluation level by using the gray clustering evaluation method, based on the types and severity of conflicts, and concluded that the outer lane in the weaving area is the most dangerous of all lanes. Chen et al. [21] proposed a micro-traffic-simulation method to analyze the influence of bus lanes on the traffic capacity of weaving areas. Rakha and Zhang [22] determined 34 different configurations of weaving and used INTEGRATION software to model weaving length and travel-demand distribution in maximum-capacity conditions. Tanaka et al. [23] developed a vehicle control algorithm to avoid the conflicts of weaving segments while improving traffic capacity. He [24] used a cellular automaton to build a weaving-area discrete model of a multilane urban expressway by analyzing vehicle characteristics. Tilg et al. [25] studied how to improve traffic capacity in weaving areas with automated vehicle technology. Cai et al. [26] obtained traffic capacity by different simulation models of weaving areas and put forward a model 
of traffic capacity in weaving areas that is appropriate for urban roads in mountainous areas. Ma et al. [27] proposed a traffic equilibrium organization method based on a lanechanging constraint in neighboring weaving areas, aiming at improving traffic efficiency and safety in weaving areas. Based on the analysis of the characteristics of safety in weaving areas, Xie et al. [28] established a collaborative control framework for the traffic in weaving areas and the areas they affect that considers control strategies of ramps and TLs. Li et al. [29] analyzed lane-changing behavior and optimized the lane-changing strategies in the upstream segments to improve road safety and capacity of the ramp areas.

However, research on spatial distribution characteristics of risk and internal optimization in municipal interchange short weaving areas is rare. This study will present an optimization method of the facilities and traffic organization in the short weaving areas of municipal interchanges.

\section{Risk and Traffic Efficiency Parameters}

When vehicles in a weaving area experience traffic conflicts due to lane changing, both the capacity and traffic risk of the weaving area are affected. Therefore, this paper focuses on identifying the distribution characteristics of traffic efficiency and risk in the weaving areas and presenting the corresponding improvement methods.

3.1. Traffic Risk Indicator. When evaluating the safety of the weaving area, traffic conflicts are usually used, namely, the ratio of the number of conflicts to the equivalent of mixed traffic. This indicator and its evaluation criteria are based on the analysis of level intersections. It is not appropriate to use the above indicators into the analysis of traffic efficiency of weaving areas. The ratio of the number of conflicts to traffic volume and weaving length is proposed on this basis, which is called the vehicle-kilometer conflicts number [30], to objectively reflect traffic safety in weaving areas:

$$
f\left(V_{r}, \mathrm{VR}\right)=\frac{\mathrm{TC}\left(L, V_{T}, V_{R}, V_{r}, \mathrm{VR}\right)}{\left(V_{T}+V_{R}\right) \cdot T} \times 1000,
$$

where $f\left(V_{r}, \mathrm{VR}\right)$ are the number of traffic conflicts per kilometer in different interweaving traffic ratio VR and interweaving ratio $V_{r} \quad$ (times/vehicle. $\mathrm{km}$ ); $\mathrm{TC}\left(L_{w}, V_{T}, V_{R}, V_{r}, \mathrm{VR}\right)$ is the total number of traffic conflicts per kilometer per hour in the different weaving length $T$; $V_{T}$ and $V_{R}$ denote the traffic volumes on the upstream mainline and entrance ramp per hour (pcu/h), respectively; VR is interweaving traffic ratio; $V_{r}$ is interweaving ratio; and $T$ is the weaving length $(\mathrm{m})$.

In Figure 1, traffic volumes from the upstream mainline to the downstream mainline and the exit ramp are set to $V_{\mathrm{FF}}$ and $V_{\mathrm{FR}}$, respectively, and the volumes from the upstream entrance ramp to mainline through movement and the downstream exit ramp are called $V_{\mathrm{RF}}$ and $V_{\mathrm{RR}}$, respectively. The total interweaving traffic volume is equal to the summation of $V_{\mathrm{FR}}$ and $V_{\mathrm{RF}}$ in this study. Thus, the interweaving traffic ratio refers to the ratio of the interweaving traffic volume to the total traffic volume on the upstream mainline and the upstream entrance ramp, and the interweaving ratio refers to the ratio of the smaller side to the larger side of $V_{\mathrm{FR}}$ and $V_{\mathrm{RF}}$.

3.2. Traffic Efficiency Indicators. Traffic delay and average weaving-area speed are selected as traffic efficiency indicators in weaving areas in this study. Delays are divided into vehicle delays on the mainline through lanes (TLs) and vehicle delays from the through lanes to the diverge lane, that is, TL delays and ramp delays. The average speed is divided into the average speed on the through lanes and that from the through lanes to the diverge lane with the corresponding to TL average speed and ramp average speed.

In summary, the risk- and traffic-efficiency-characterization parameters of weaving areas are selected as shown in Table 1.

\section{Experiments}

PTV-VISSIM is a microscopic simulation tool based on the time interval and driving behavior, which is often used for modelling urban traffic and public transportation operations. This study established the selected weaving-area model via the VISSIM interface to set traffic parameters (e.g., the proposed traffic volume, expected speed, and traffic volume composition, entered to simulate the traffic flow operations under specific conditions in the weaving area) and further obtain the conflict rate, delay, and average speed, as well as other data used to develop research on the influence of various parameters on the risk and traffic efficiency characteristics of weaving areas.

4.1. Simulation Parameters. To study the traffic flow characteristics of weaving areas under different road conditions, input values of the simulation parameters should be selected. After the simulation parameters are determined, traffic simulation is used to combine different influencing factors, and then the law of traffic flow operation and risk characteristics in the weaving area of the interchange section is analyzed. Based on the common municipal short-weavingarea configuration, one can select the typical scenario of having the three-lane single-side weaving of the TL and the double-entry and single-exit form of the ramp entrance and exit to construct a model for traffic simulation.

4.1.1. Weaving Length. In this study, the length of the weaving area borrows the maximum weaving length formula proposed in the United States Highway Capacity Manual (HCM 2010). Based on it, the calculation shows that the maximum length is $750 \mathrm{~m}$; meanwhile, the minimum weaving zone length determined by Wang et al. [31] research is set to $150 \mathrm{~m}$.

4.1.2. Traffic Volume. As usual, the traffic volume can be predicted after collecting and sorting the historical data, which is used to carry out a series of analysis experiments 


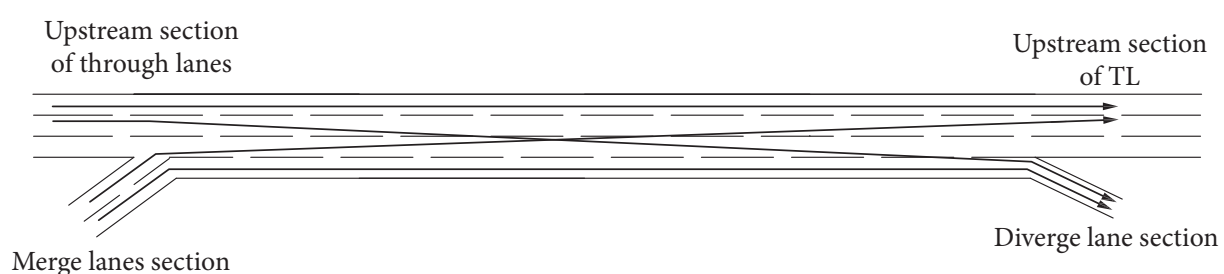

Figure 1: The layout of the weaving area.

TABle 1: List of risk and traffic efficiency index settings of weaving areas.

\begin{tabular}{lc}
\hline Detection index & Index explanation \\
\hline $\begin{array}{l}\text { Vehicle-kilometer conflicts } \\
\text { Ramp delay }\end{array}$ & The ratio of the number of conflicts to throughput and weaving length \\
TL delay & Delay time from TL to diverge lane \\
Average ramp speed & Delay time on TL \\
Average TL speed & Weaving length/travel time from TL to diverge lane \\
Weaving length/travel time on TL
\end{tabular}

and improvements. Chen et al. [32-34] proposed a prediction method for traffic volume and shipped type based on the neural network model, which is referred to the design capacity of TL lanes and ramps specified in relevant codes [35], as shown in Tables 2 and 3. In this study, the design capacity in the code is selected as the intermediate value of the simulation test group. The selected range of the traffic volume on the two-lane ramp at $60 \mathrm{~km} / \mathrm{h}$ is $2100-2500$ vehs/ $h$ and the step length is set to 100 vehs/h; the traffic volume of the three-lane TL at $80 \mathrm{~km} / \mathrm{h}$ is selected in the range $2700-3900 \mathrm{vehs} / \mathrm{h}$ and the step length is $300 \mathrm{vehs} / \mathrm{h}$. The simulation experiment results show that the weaving phenomenon in the weaving area is serious under the abovementioned traffic volume parameter settings. To prevent the occurrence of traffic congestion, while taking into account the influence of the proportion of large vehicles, the selected value and step length of the traffic volume of the ramp and TL are further reduced to $2 / 3$ of the original design. It was determined in this study that the $60 \mathrm{~km} / \mathrm{h}$ two-lane ramp traffic range is $1400-1680$ vehs/h and the step length is $70 \mathrm{vehs} / \mathrm{h}$; the $80 \mathrm{~km} / \mathrm{h}$ three-lane through-line traffic volume is $1800-2600$ vehs/h and the step length is $200 \mathrm{vehs} / \mathrm{h}$. The simulation tests show that some sections of the weaving area still exhibit traffic congestion. After more in-depth debugging and optimization selections, the final selection of the TL traffic volume is 1800 vehs/h and the ramp traffic volume is $1400 \mathrm{vehs} / \mathrm{h}$ as the fixed traffic volume parameters in the final simulation experiment.

4.1.3. Interweaving Traffic Ratio. The applicable interlaced flow ratios of each interlaced configuration are different, and a wide range of values may exceed capacity and cause traffic congestion. So, the value in this study is $0.1-0.3$ with a step size of 0.05 .

4.1.4. Interweaving Ratio. Diao [36] found that the change of the interweaving ratio has no significant impact on the
TABle 2: Design capacity of basic ramp sections.

\begin{tabular}{lccccccc}
\hline $\begin{array}{l}\text { Ramp design speed } \\
(\mathrm{km} / \mathrm{h})\end{array}$ & 80 & 70 & 60 & 50 & 40 & 35 & 30 \\
\hline Single lane & 1500 & 1400 & 1300 & 1200 & 1000 & 900 & 800 \\
Double lane & 2900 & 2600 & 2300 & 2000 & 1700 & 1500 & 1300 \\
\hline
\end{tabular}

operating efficiency and safety of the weaving area, so the interweaving ratio is fixed at 0.5 .

4.2. Variance Analysis of Influencing Factors. In order to evaluate the impact of the fluctuation of the experimental data on the results, this study employs the analysis of variance method to test the degree of influence of the respective variables on the results and to determine the main influencing factors. SPSS 12.0 software was used as the dataprocessing method of variance analysis, and the characteristics of the influence of various factors on the indicators are obtained as shown in Figure 2.

From Figure 2, one can find that the weaving length has the greatest impact on traffic safety and efficiency and has a significant impact on the conflict rate, ramp delays, and average speed of the mainline and ramp traffic; ramp traffic has a greater impact on traffic safety and efficiency and has a significant impact on ramp delay. The interweaving traffic ratio and through-movement traffic volume have less impact on traffic safety, and the through-movement traffic volume has a greater impact on traffic efficiency than the interweaving traffic ratio. According to the analysis results, the sequence of the importance degree of each influencing factor is as shown in Table 4.

4.3. Risk Spatial Distribution of Weaving Areas. The results of the above experiment show that ramp length and ramp capacity have the greatest influence on driving risk and traffic efficiency. Further, the distribution characteristics of traffic risk are analyzed for different weaving-segment 
TABLE 3: Traffic volume threshold on single-lane expressway under level-of-service (LOS).

\begin{tabular}{|c|c|c|c|}
\hline Ramp design speed $(\mathrm{km} / \mathrm{h})$ & 120 & 100 & 80 \\
\hline Traffic volume upperbound under the 2 nd grade of LOS & 1200 & 1150 & 1100 \\
\hline Traffic volume upperbound under the 3rd grade of LOS & 1650 & 1600 & 1500 \\
\hline
\end{tabular}

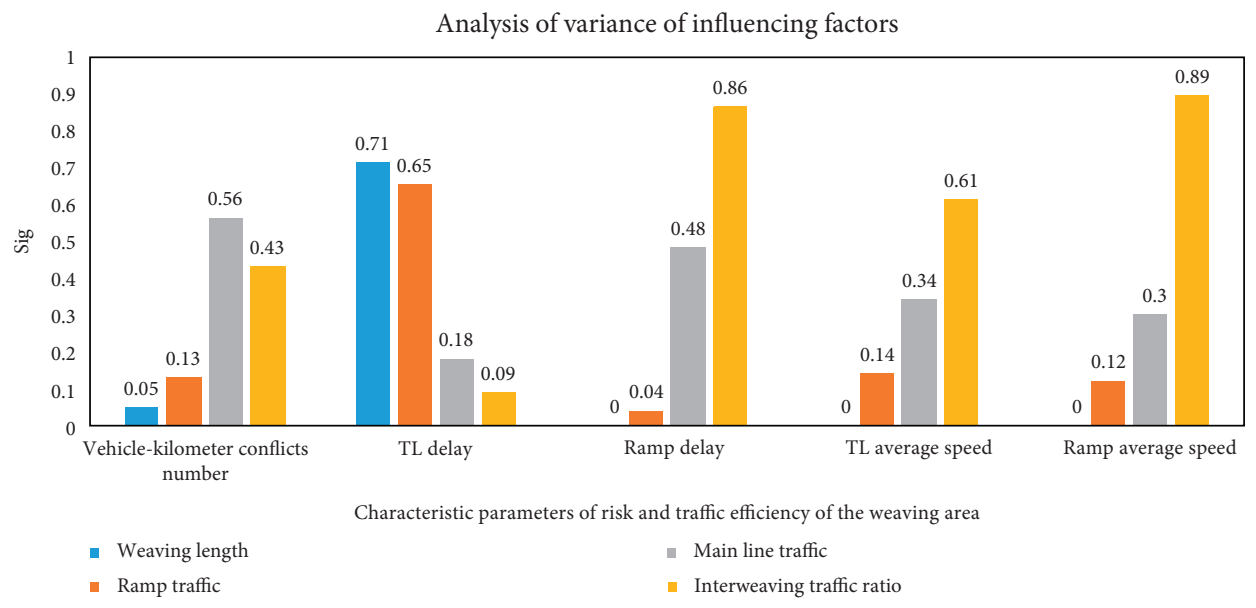

FIGURE 2: Analysis of variance.

TABLE 4: The sequence of the importance degree of each influencing factor on traffic safety and efficiency under the analysis of variance.

\begin{tabular}{|c|c|c|c|c|c|c|}
\hline Rank & Vehicle-kilometer conflicts & Number of conflicts & TL delay & Ramp delay & TL average speed & Ramp average speed \\
\hline Weaving length & 1 & 1 & 1 & 1 & 1 & 1 \\
\hline Ramp traffic & 2 & 2 & 2 & 2 & 2 & 2 \\
\hline TL traffic & 4 & 3 & 3 & 3 & 3 & 3 \\
\hline Weaved traffic ratio & 3 & 4 & 4 & 4 & 4 & 4 \\
\hline
\end{tabular}

lengths in municipal interchanges. If the length of the weaving segment is too short, the lane-change behavior is prone to congestion, and the internal risk cannot be reflected by the speed and acceleration. Meanwhile, the longer the length of the short interweaving area is, the less the concentration of risk will become because there are much more opportunities and options for drivers to change lanes. In our experiments, the weaving lengths are set to 350,450 , and $550 \mathrm{~m}$. According to the design requirements of Tables 2 and 3 and simulation experiment debugging, the traffic volume of the TL is 1800 vehs/h, while the traffic volume of the ramp is set as $1400 \mathrm{vehs} / \mathrm{h}$. The locations of detection devices to collect traffic parameters are shown in Figure 3.

The mean acceleration and deceleration, acceleration range, deceleration range, and speed standard deviation of each lane and section are selected as the characteristic parameters in the experiments. Among them, the mean acceleration and deceleration can reflect the fluctuation of acceleration and deceleration at the detection location. The larger the mean value, the greater the speed variation range and the greater the corresponding risk [37]. The greater the speed range of addition and subtraction, the greater the probability of traffic collision. The speed standard deviation can reflect the dispersion degree of vehicle speed at the particular section. Generally speaking, the greater the degree of dispersion, the lower the safety of the location. Those five performance indexes are shown in Figures 4-8.

As can be seen in Figure 4, the mean acceleration in the inner and middle lanes is stable below $0.4 \mathrm{~m} / \mathrm{s}^{2}$. The mean acceleration reaches a maximum at the merge and diverge sections, while travel speed in the outer lane fluctuates greatly. The mean acceleration exceeds $0.4 \mathrm{~m} / \mathrm{s}^{2}$, reaching up to $0.66 \mathrm{~m} / \mathrm{s}^{2}$ at the entrance of the outer lane when the weaving length is $550 \mathrm{~m}$. Because the vehicle speed in the auxiliary lane is lower than one in the mainline through movement when the ramp traffic flows into the downstream mainline, the mean acceleration in the auxiliary lane is smaller than one in the outer lane. Also, the mean acceleration of each lane section in the exit ramp increases significantly, indicating that the risk in the exit part of the weaving area increases similarly.

As can be seen in Figure 5, the mean deceleration of each lane section is maintained at $0.2 \mathrm{~m} / \mathrm{s}^{2}$. At the $3 / 4$ section of the weaving area, the peak value of the mean deceleration appears. When the length of the weaving section is $350 \mathrm{~m}$, the mean deceleration reaches $1.365 \mathrm{~m} / \mathrm{s}^{2}$. The value in the auxiliary lane remains at a low level from the entrance to the $3 / 4$ section and is stable below $0.2 \mathrm{~m} / \mathrm{s}^{2}$. However, it significantly increases at the segment from the $3 / 4$ section to the exit, mainly due to differences in traffic speeds between the 


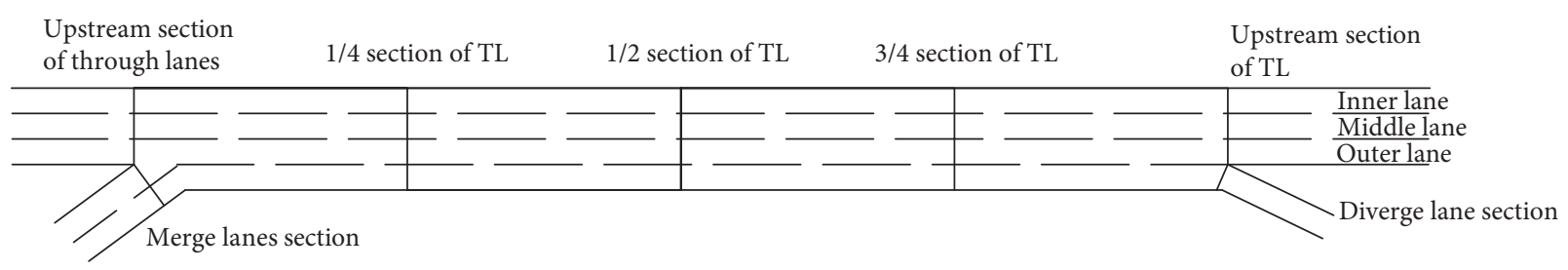

FIgURE 3: Diagram of the location setting of detection to collect test data.

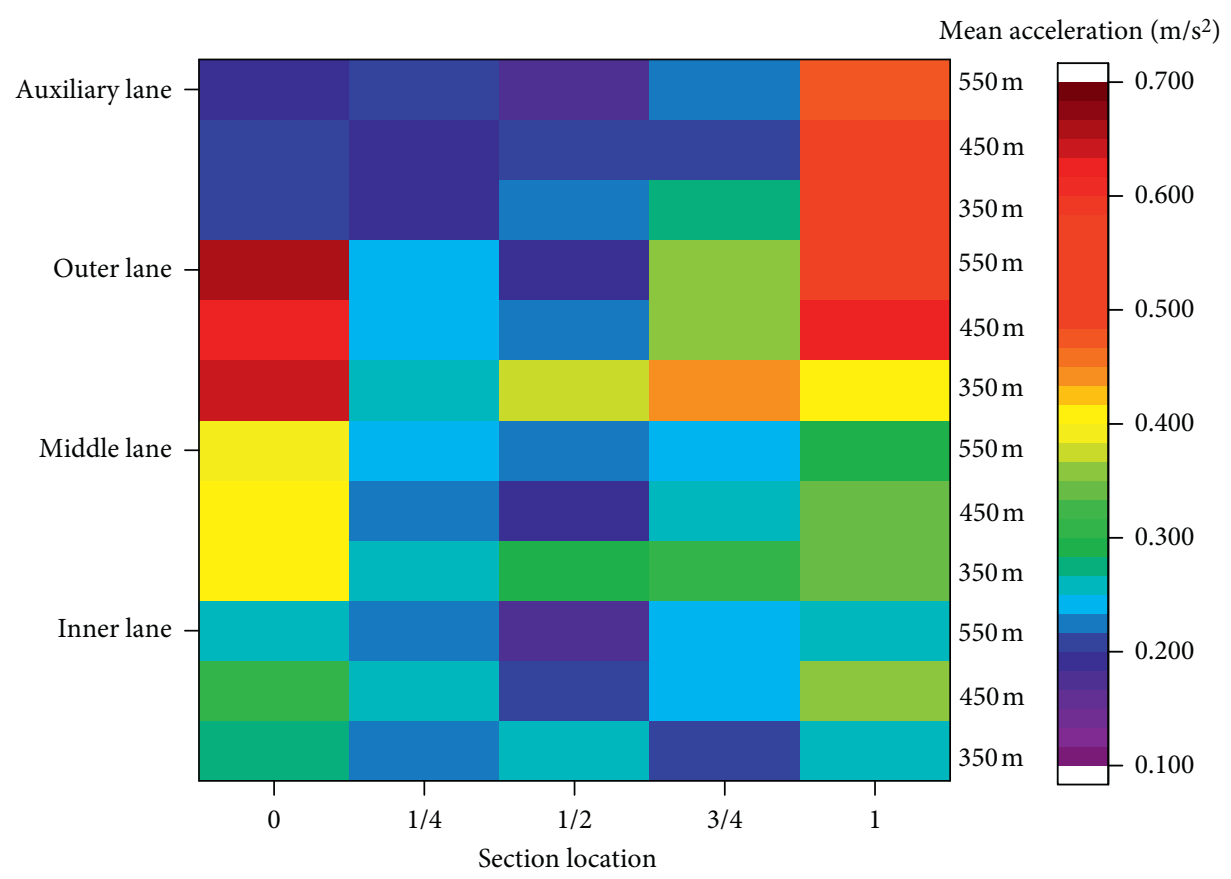

Figure 4: Distribution diagram of mean acceleration at sections of each lane.

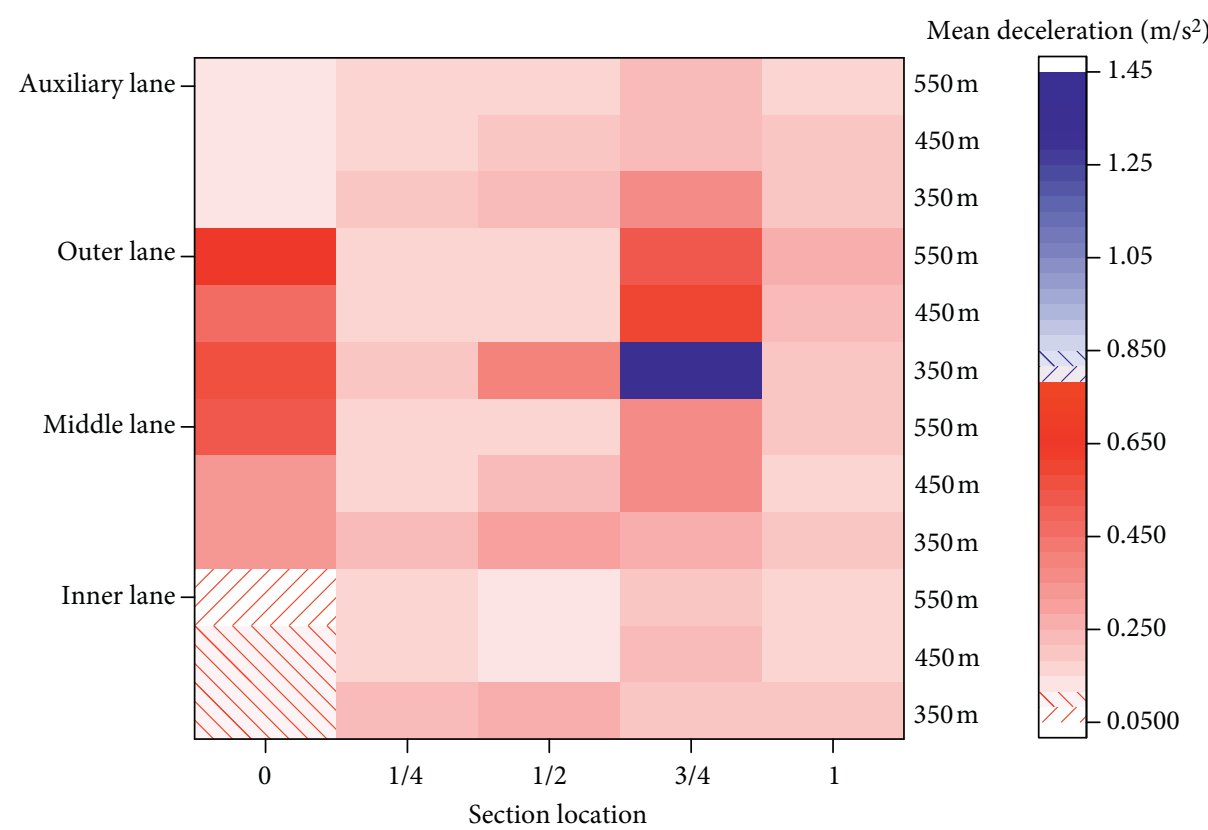

FIgURE 5: Distribution diagram of mean deceleration at different positions. 


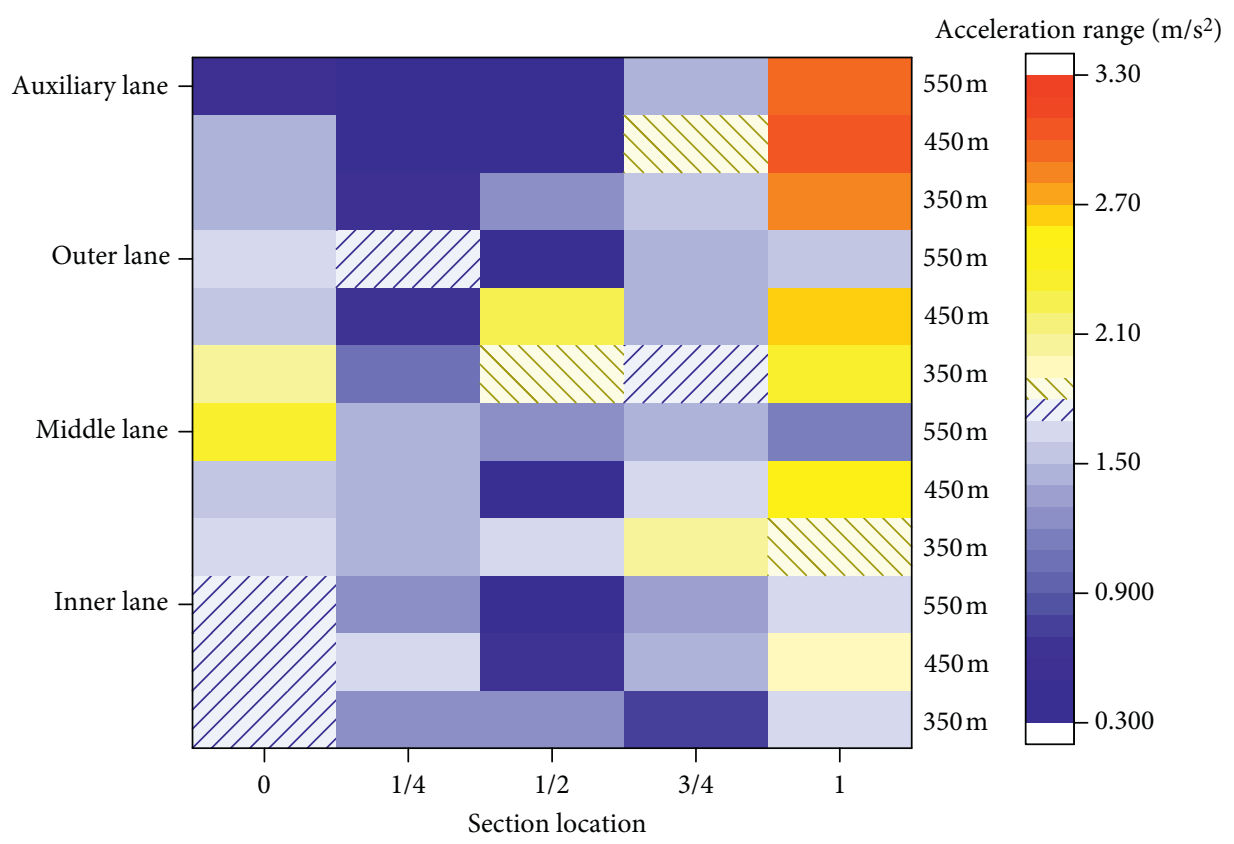

(a)

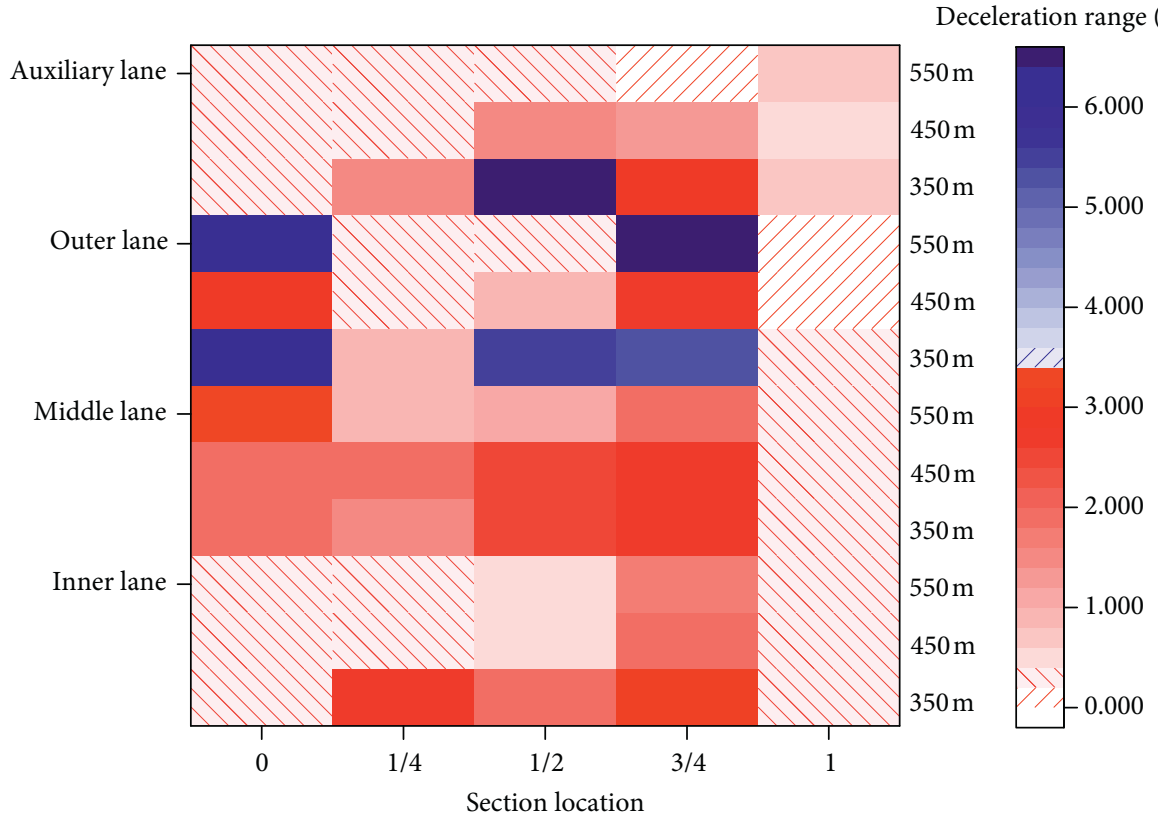

(b)

FIgURE 6: Distribution diagram of acceleration and deceleration ranges at different positions. (a) The acceleration range. (b) The deceleration range.

outer and auxiliary lanes causing the design speeds of the ramp and downstream mainline to be different, as well as to frequent braking during lane changing. The mean deceleration in the diverge area under various lengths decreases. Thus, it can be seen that the deceleration behavior is mainly concentrated in the $3 / 4$ section, which should be regarded as an important area of risk control.

Similarly, one can find that the difference between the acceleration range and deceleration range is large at the different section belonging to different lanes in Figure 6. In general, the range in the diverge area is larger than one at the other sections. The vehicles entering the lane leave at a high acceleration, which forms the acceleration difference between themselves and the vehicles ahead that has reached a certain speed. The acceleration range between the inner and auxiliary lanes before the $3 / 4$ section generally reaches a low level. The inner lane is less disturbed, while the low acceleration demand of the segment before the $3 / 4$ section occurs in the auxiliary lane. The vehicles move smoothly and braking is less related to lane-changing behavior. 


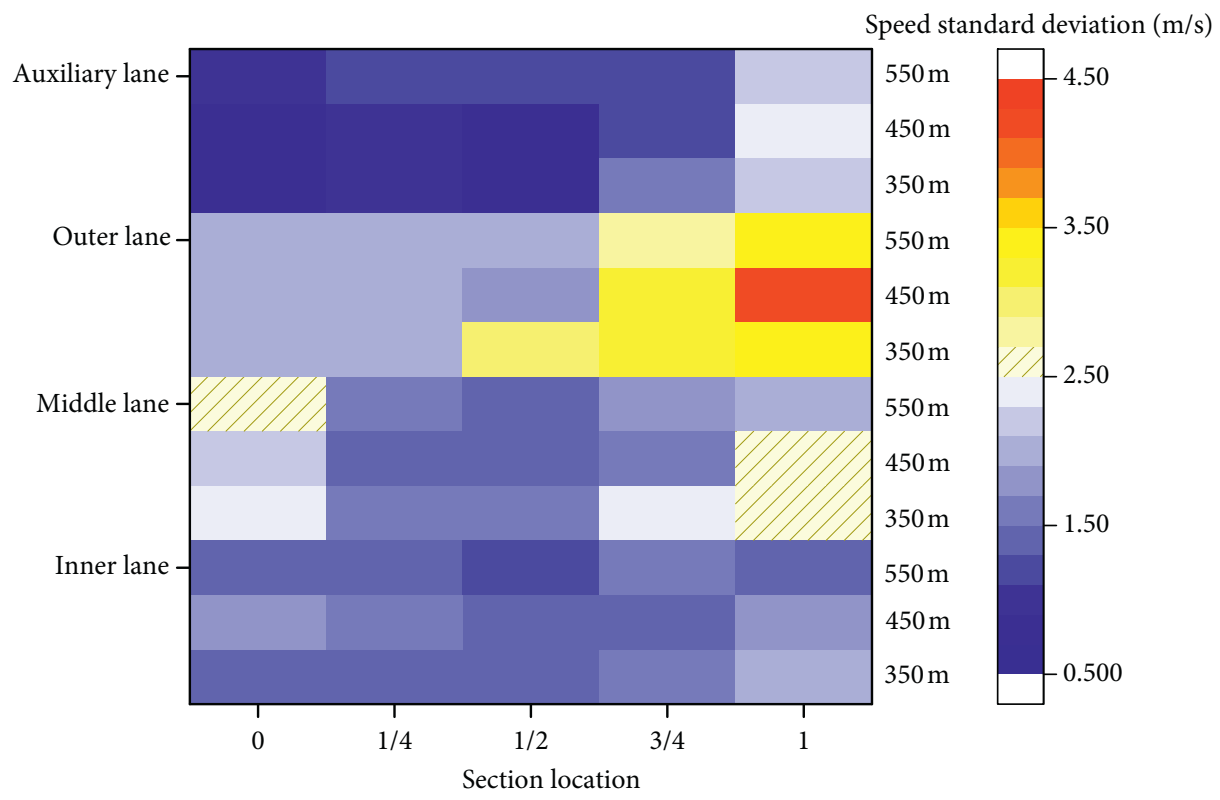

Figure 7: Distribution diagram of speed standard deviation at different positions.

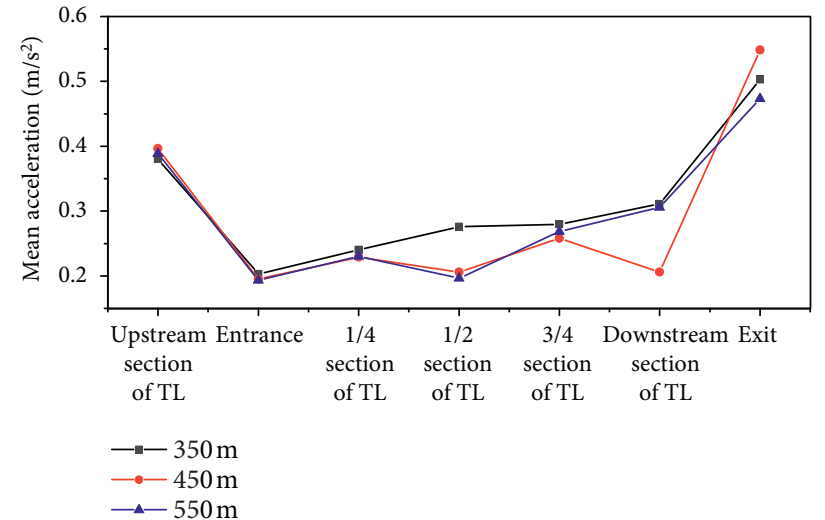

(a)

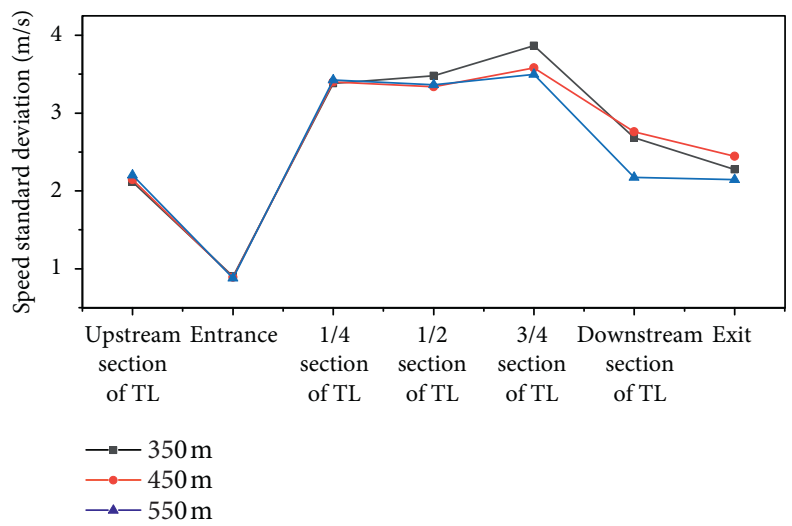

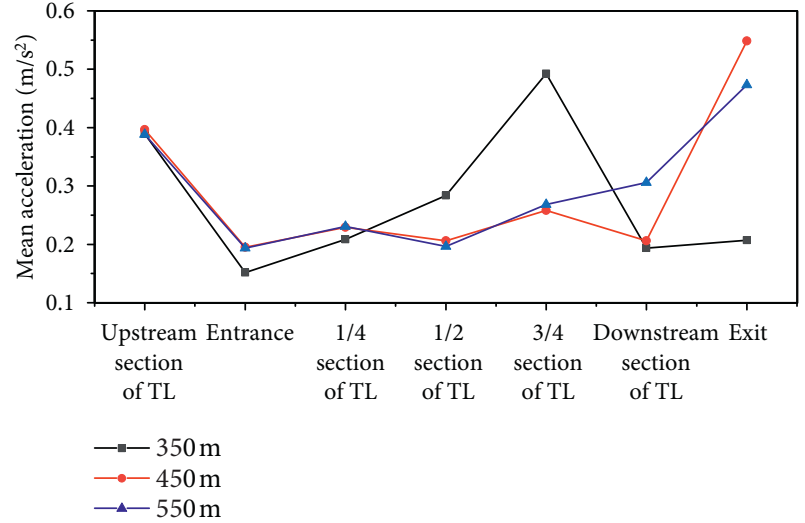

(b)

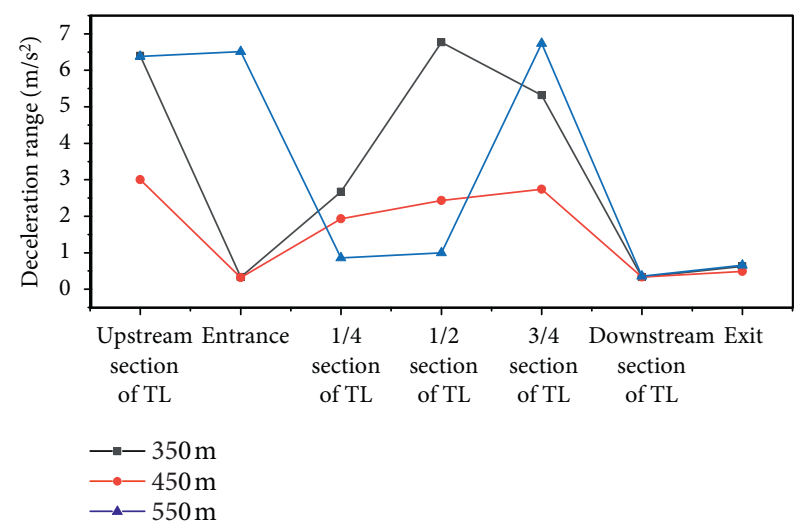

(d)

Figure 8: Continued. 


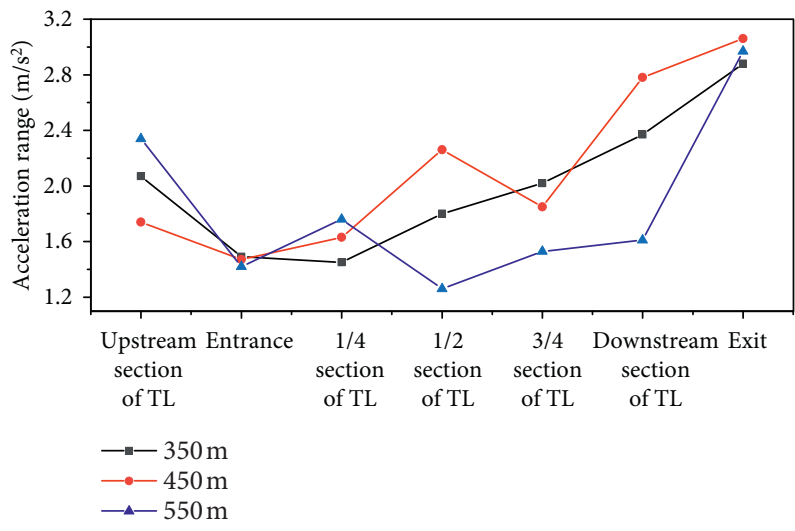

(e)

FIGURE 8: Distribution diagram of five characteristic parameters at the overall section.

Figure 7 shows that the peak of speed standard deviation appears at the similar location regardless of the weaving length, which is mainly concentrated in the middle and outer lanes. When the vehicle is in the middle lane, the driver can change lanes to the inside or outside, which may easily lead to acceleration and deceleration to change lanes safely. However, when the vehicle is in the outside lane, lane-changing to the auxiliary lane is facilitated, and then the vehicle can safely drive off the mainline to the ramp, which will also lead to a large speed deviation in the auxiliary lane.

According to the overall section of Figure 8, the peak of previous five parameters is high at the section which is from the entrance and $3 / 4$ sections in the main weaving segment to the exit section, including the exit in the auxiliary lane. Regarding the $1 / 4,1 / 2$, and $3 / 4$ sections, the speed standard deviation of vehicles in the weaving area is quite large because of traffic speed difference.

Referring to the above analysis, the indicators of the downstream segment in the $350 \mathrm{~m}$-long weaving areas are generally larger than ones in weaving areas of other lengths, illustrating that short weaving lengths have a certain influence on risk distribution. In short weaving areas of municipal interchanges, the probability of risk occurrence is the highest in the $3 / 4$ section and exit position of the outer lane. Near to the exit, drivers would decide to slow down to complete lane changing, causing vehicle drivers behind those in front to also slow down to complete lane changing to avoid collisions. Meanwhile, some drivers change lanes only when approaching the exit, which increases risk at the exit section or in its immediate vicinity. Thus, the $3 / 4$ and exit sections of the outer lane should be regarded as the critical control point of risk reduction. The fluctuation of the mean acceleration and acceleration range in the auxiliary lane is not significant, which is caused by low-speed vehicles entering the weaving area. As a result, the two indexes above are smaller than those in other lanes, which reduces the probability of risk conflicts. However, in short, risk control measures should be adopted in the diverge-lane segment of the auxiliary lane.

\section{Optimal Method}

According to the aforementioned simulation analysis, the conflict risk in the mainline is concentrated in the $3 / 4$ section and exit in the outer lane. The risk reduction optimal method is proposed and is simulated for different weaving lengths in Guangdong Province, China. Referring to method requirements of traffic marking of entrances and exits for highways in Guangdong Province, a solid-lane line shall be set between the inside and middle lanes or between the middle and outer lanes. The length of the solid-lane line should not be less than the distance from the start point of the transition region to the tip of the barrier. Meanwhile, the solid-lane line of the inner and middle lanes should be extended forward for a certain length.

Kang and Huang [38] reported that a certain lanechange length is required when a vehicle is changing lanes. It is assumed that the vehicle enters the middle lane when the driver changes lanes before the beginning of the solid-lane line. The length that can ensure that a vehicle can successfully change lanes into the outer lane should be no larger than $L$. This length includes the length matched by vehicle speed as it accelerates and the lengths that the driver can confirm and import into the middle lane, which are denoted as $l_{1}$ and $l_{2}$. If it is assumed that vehicles in the inner and middle lanes drive at the same speed, the length $l_{1}$ matched by vehicle speed as it accelerates is equal to 0 . Also, the driver's reaction time will change with the transformation of traffic environment complexity. The total response time of drivers is approximately $0.5-4.0 \mathrm{~s}$, but the complexity of a municipal interchange connection is lower, so $2 \mathrm{~s}$ is taken.

The travel distance for such a reaction time can be represented by

$$
L=l_{1}+l_{2}=l_{2}=\frac{v_{1}^{2}-v_{0}^{2}}{2 a}+\frac{V}{3.6} t,
$$

where $v_{0}$ is vehicle speed in the inner lane of the downstream mainline $(\mathrm{m} / \mathrm{s}) ; v_{1}$ is the speed at which the vehicle accelerates from the inner lane to the middle lane $(\mathrm{m} / \mathrm{s}) ; a$ denotes the acceleration $\left(\mathrm{m} / \mathrm{s}^{2}\right) ; V$ is the design speed in the 


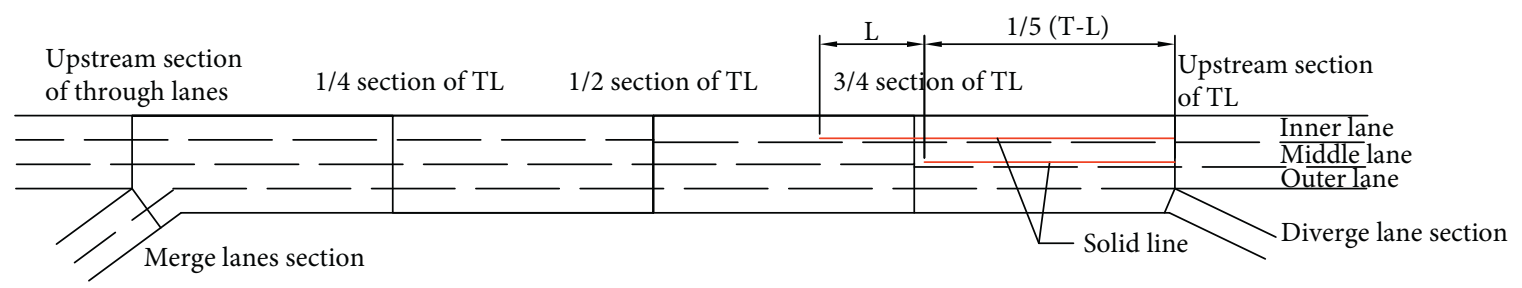

FIgURE 9: Diagram of optimal method in weaving area.

downstream mainline $(\mathrm{m} / \mathrm{s})$; and $t$ represents the response time of drivers (s).

Therefore, it is calculated that $L=l_{1}+l_{2}=0+$ $44.44=44.44 \mathrm{~m}$, and $L=50 \mathrm{~m}$ is used to ensure safety. When the length of the solid-lane line is set between the middle and outer lanes as $1 / 4$ of the length of the weaving segment, the calculation shows that the ratio of the solid line between the middle lane and the inner lane to the weaving segment is too high, especially the length of the weaving segment is shorter, such as $T=150 \mathrm{~m}$. Meanwhile, it is necessary to ensure that there is enough length for vehicles to complete lane changing. It is thus more appropriate to set the length of the solid-lane line as $1 / 5(T-L)$. The driving conditions in the middle and inside lanes are better than those in the outer and auxiliary lanes. Also, when researching the risk in short weaving areas, vehicles should be allowed to change from the outer to the middle lane or from the middle to the inner lane. The optimal method is shown in Figure 9.

It is calculated that the lengths of the solid-lane line between the middle and outer lanes are 60, 80, and $100 \mathrm{~m}$ when the weaving lengths are 350,450 , and $550 \mathrm{~m}$, respectively. The model simulation was carried out for the optimization, and the rationality and applicability of design were analyzed by the mean acceleration, acceleration range, and speed standard deviation. The analysis results are shown in Figures 10-12.

One can find that the acceleration of mean absolute from the entrance to the $1 / 2$ section fluctuates within $0.05 \mathrm{~m} / \mathrm{s}^{2}$, within a small fluctuation range in Figure 10. However, there is also a good case that the index decreases by $0.1 \mathrm{~m} / \mathrm{s}^{2}$ in the model in which the weaving length is $350 \mathrm{~m}$. From the $3 / 4$ section to the exit in the outer lane, the change range of the index fluctuates within $0.05 \mathrm{~m} / \mathrm{s}^{2}$. At $3 / 4$ section, the average acceleration indicator of the model with the weaving length of $350 \mathrm{~m}$ and $550 \mathrm{~m}$ produced a decrease of more than 0.1 and $0.3 \mathrm{~m} / \mathrm{s}^{2}$, respectively, which significantly reduces the probability of risk. At the exit, however, the mean acceleration increases by approximately no more than 0.1 and $0.2 \mathrm{~m} / \mathrm{s}^{2}$, respectively, while the mean acceleration decreases by approximately no more than $0.15 \mathrm{~m} / \mathrm{s}^{2}$ in the model in which the weaving length is $450 \mathrm{~m}$. At the $3 / 4$ section in which the risk is concentrated, vehicles in the inside and middle lanes are forbidden to be driven to the outside lane, which reduces the chance of weaving and the probability of risk. However, because vehicles in the outer and auxiliary lanes are allowed to merge into the middle and inner lanes, with better traffic conditions in the middle and inner lanes, it is equivalent to balancing risks in the entire weaving area and reducing the risk concentration.
Correspondently, Figure 11 shows that the acceleration range from the entrance to the $1 / 4$ section fluctuates within $1 \mathrm{~m} / \mathrm{s}^{2}$, within a small fluctuation range. Since the optimal traffic setting is concentrated in the $3 / 4$ section to the exit, it has little influence on this segment. An increase of not more than $2 \mathrm{~m} / \mathrm{s}^{2}$ of the acceleration range was generated in the inner and middle lanes at the $1 / 2$ section. For different weaving lengths, the range of $2-6 \mathrm{~m} / \mathrm{s}^{2}$ decreases for the acceleration range, which reduces the acceleration range at the risk-concentration position. This indicator has a different degree of decline in each lane, especially at the $3 / 4$ section. For the weaving areas of $350 \mathrm{~m}$ and $550 \mathrm{~m}$ lengths, the performance index shows a large decrease of more than 2 and $5 \mathrm{~m} / \mathrm{s}^{2}$, respectively. Furthermore, the acceleration range at the exit does not have a range of more than $4 \mathrm{~m} / \mathrm{s}^{2}$, and the variation value fluctuates slightly within the range of $2 \mathrm{~m} / \mathrm{s}^{2}$. The main reason is that after traffic optimization, vehicles in the inner and middle lanes are prohibited from changing into the outer lane at the $3 / 4$ section where high risk exists, reducing weaving and the probability of risk.

Subsequently, Figure 12 shows that the speed standard deviation of other models changes by no more than $0.2 \mathrm{~m} / \mathrm{s}$ from the entrance to the $1 / 2$ section, except for the outer lane of the $350 \mathrm{~m}$-length weaving area. Due to traffic optimization, drivers in the inner lane and the middle lane will take measures to change lanes in advance, which leads to the increase of speed standard deviation. At the $3 / 4$ section, the speed standard deviation is mainly decreased, especially in the outside lane. Under the $550 \mathrm{~m}$-length weaving scenario, the decrease of speed standard deviation reaches a maximum in this section, i.e., by more than $0.5 \mathrm{~m} /$ s. At the same time, the speed standard deviation at the exit in different models presents a downward trend for the most part. The decrease of the outer lane with a length of $450 \mathrm{~m}$ is greater than $0.8 \mathrm{~m} / \mathrm{s}$. This is the result of banning lane changing in the inside and middle lane, which leads to fewer vehicles merging into the weaving area, thus ensuring the safety of exiting in the outside lane. Also, the increase of the speed standard deviation in the outer lane under the $550 \mathrm{~m}$-length weaving scenario is greater than $0.6 \mathrm{~m} / \mathrm{s}$, which should be caused by the weaving of vehicles in the outer and auxiliary lanes.

To summarize, the optimization scheme transfers the risk to the segment with good driving conditions and low risk, which has a good risk-reduction effect for the riskconcentration segments from the $3 / 4$ section to the exit in the outer and auxiliary lanes. This is beneficial to improve traffic safety in the short weaving areas of municipal interchanges. 


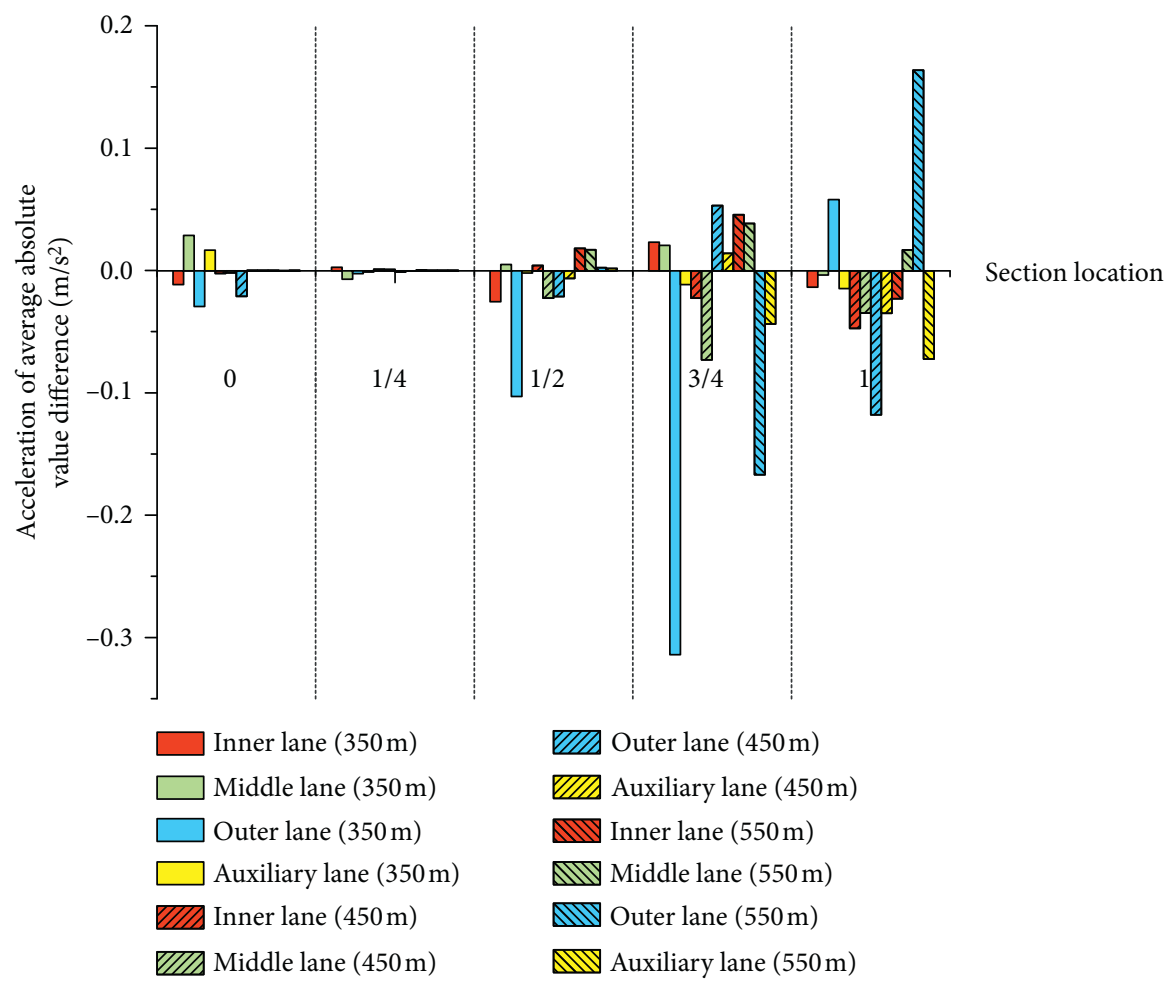

FIGURE 10: The acceleration of mean absolute difference between two schemes.

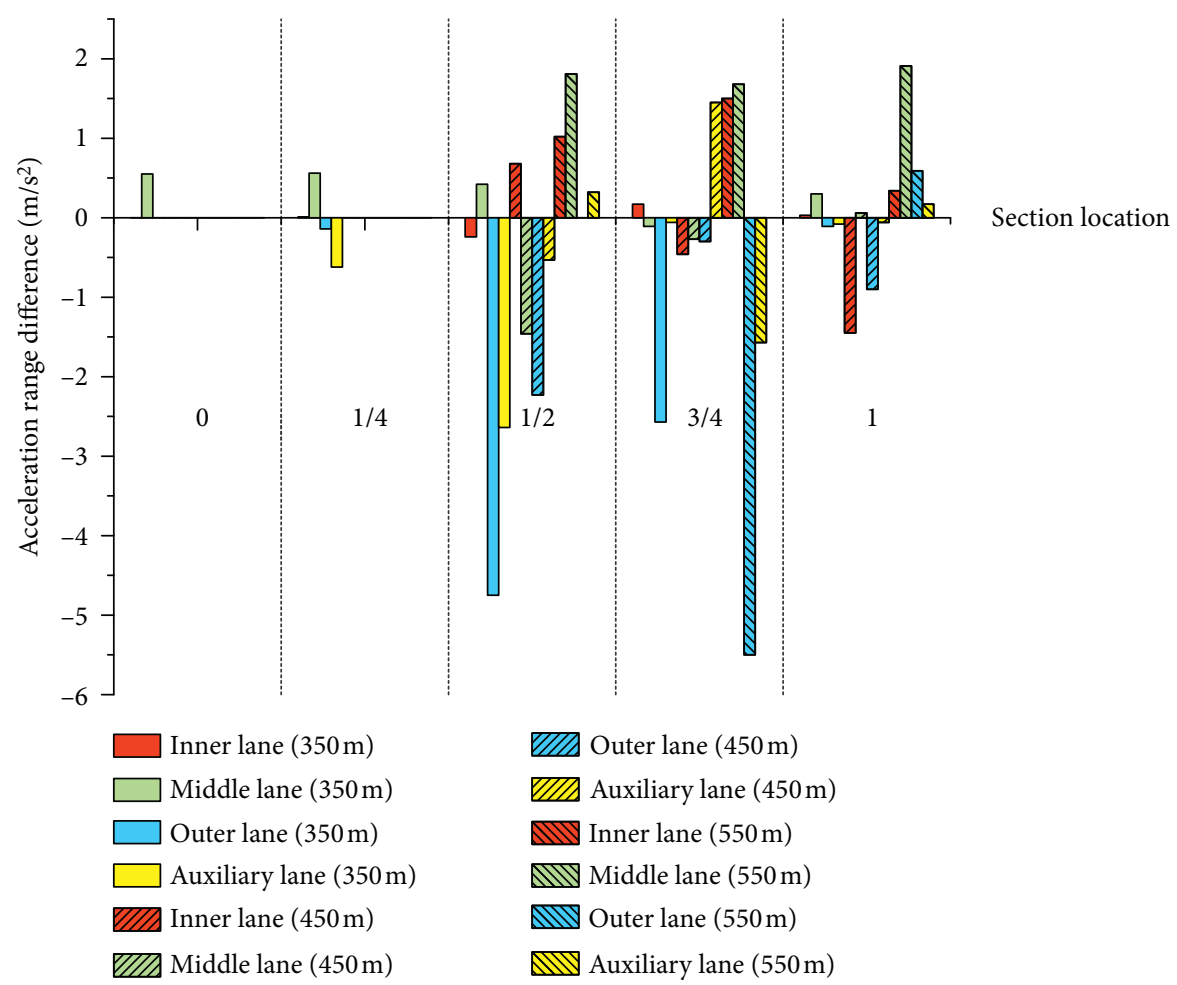

FIgURE 11: The acceleration range difference between the two schemes. 


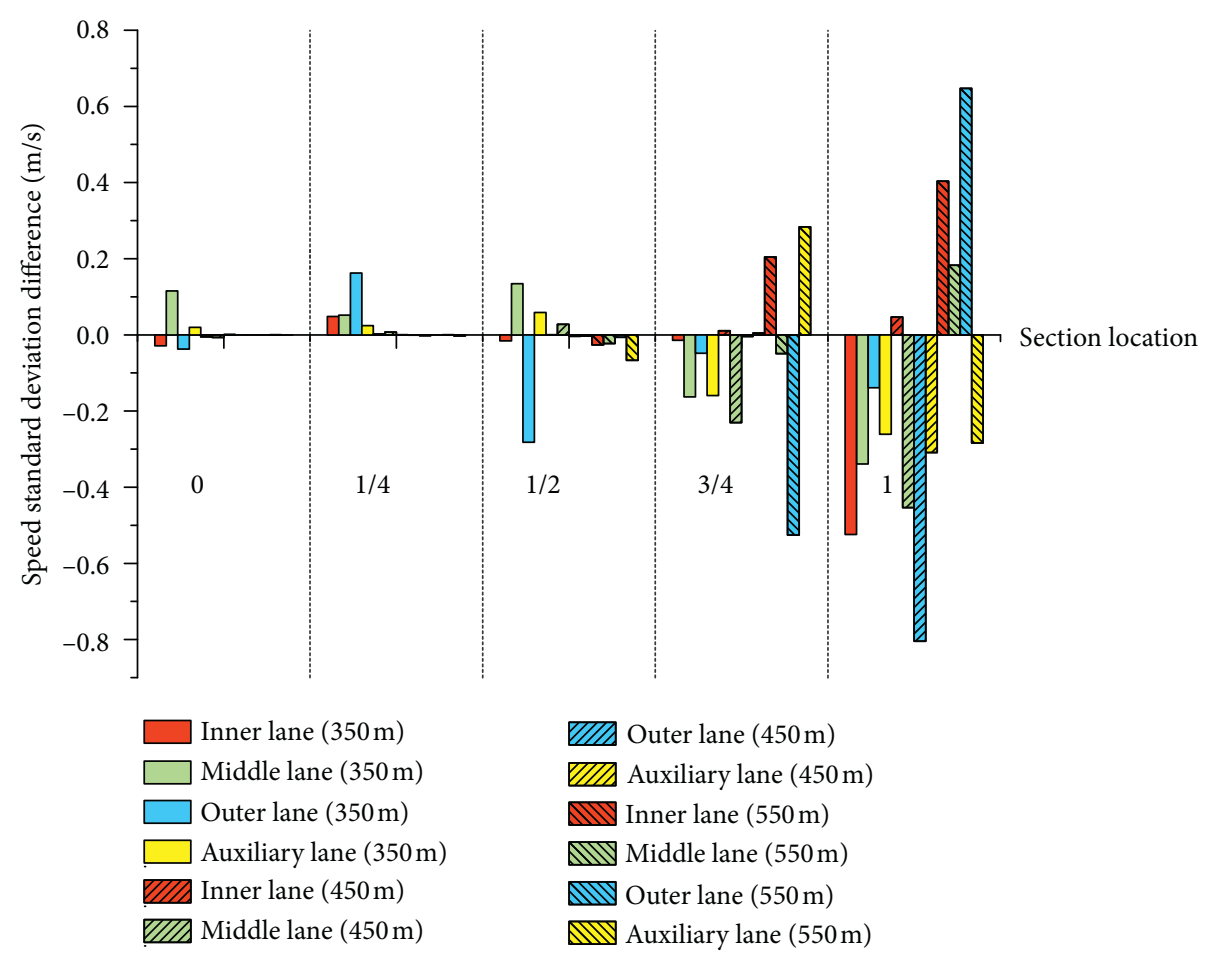

Figure 12: The speed standard deviation difference between the two schemes.

\section{Conclusions and Recommendations}

Quite a few problems in the construction and operation of municipal interchanges could lead to reduced traffic efficiency and increased risks, especially in weaving areas. To ensure traffic efficiency and safety in the weaving areas of municipal interchanges, the typical double-entrance and single-exit weaving areas in municipal interchanges are taken as the research object in this paper. The conflict rate, ramp delay, TL travel delay, ramp average, and TL average are selected to quantitatively describe traffic efficiency, and then the main influencing factors are recognized. Subsequently, further analysis of risk distribution shows that a short length of weaving areas would increase risk probability. The comprehensive analysis shows that the risk probability is highest at the $3 / 4$ and downstream sections in the outer lane inside municipal interchange short weaving areas, and so these two sections in the outer lane should be regarded as the critical control point of risk reduction. Besides, risk-control measures should also be applied to auxiliary lane exits to ensure vehicle safety. Finally, an optimal method for the high-risk segments in weaving areas is carried out to verify the developed risk distribution characteristics and optimal method. The results can provide a reference for the optimization method of facilities and traffic organization in municipal interchange short weaving areas.

The factors affecting traffic efficiency and spatial distribution characteristics of risks in complex municipal interchanges are explored in this paper. However, the effect of the optimization method is based on the increase or decrease of the detection section index value, and so this study only focuses on the location of risk concentration without recognizing the probability of risk occurrence and distribution of other detection sections after optimization. In the future, it is necessary to collect field data to validate the reliability and effectiveness of the proposed method under various geometric configurations and traffic demand patterns in urban short weaving areas and estimate the probability of traffic accident occurrence.

\section{Data Availability}

The data used to support the findings of this study are available from the corresponding author upon request.

\section{Conflicts of Interest}

The authors declare that there are no conflicts of interest regarding the publication of this paper.

\section{Acknowledgments}

This study was supported by the National Natural Science Foundation of China (grant no. 51878297), Natural Science Foundation of Guangdong Province (grant no. 2019A1515011477), Fundamental Research Funds for the Central Universities of South China University of Technology (grant no. 2020ZYGXZR093), and Guangdong Provincial Key Laboratory of Modern Civil Engineering Technology (no. 2021B1212040003).

\section{References}

[1] H. Chen, Traffic Efficiency Comparative Analysis and Optimal Design of Ramp Combinations in Urban Expressway, Shanghai Jiao Tong University, Shanghai, China, 2015. 
[2] M. Li, "Research and application on arrangement of urban elevated expressway "first in and after out" ramp," Urban Roads Bridges \& Flood Control, vol. 7, pp. 53-55, 2016.

[3] Z. Huang and K. Chen, "Research on the minimum spacing of expressway ramps with first entry and exit," Journal of China \& Foreign Highway, vol. 36, no. 4, pp. 335-340, 2016.

[4] X. Pan, "Discussing the scheme for the insufficient spacing between the entrances and exits of expressways," Engineering Technology Research, vol. 4, no. 4, pp. 207-208, 2019.

[5] J. A. Bonneson, Highway Safety Manual, American Association of State Highway and Transportation Officials, Washington, DC, USA, 2010.

[6] China Highway Engineering Consulting Group Co., Ltd., Design Rules for Highway Interchanges, China Highway Engineering Consulting Group Co., Ltd., Beijing, China, 2014.

[7] L. Wang, M. Abdel-Aty, Q. Shi, and J. Park, "Real-time crash prediction for expressway weaving segments," Transportation Research Part C: Emerging Technologies, vol. 61, pp. 1-10, 2015.

[8] M. Abdel-Aty and L. Wang, "Implementation of variable speed limits to improve safety of congested expressway weaving segments in microsimulation," Transportation Research Procedia, vol. 27, pp. 577-584, 2017.

[9] B. Wang, L. Gao, and Z. Juan, "Analysis of lane changing conflict based on TTA in expressway weaving area," Xitong Fangzhen Xuebao/Journal of System Simulation, vol. 30, pp. 3306-3311, 2018.

[10] C. Li, Y. Chen, and X. Xing, "Optimization and safety evaluation of collector-distributor road connection waving area for composite interchange," Highway Engineering, vol. 43, pp. 120-125, 2018.

[11] J. Yuan, M. Abdel-Aty, Q. Cai, and J. Lee, "Investigating drivers' mandatory lane change behavior on the weaving section of freeway with managed lanes: a driving simulator study," Transportation Research Part F: Traffic Psychology and Behaviour, vol. 62, pp. 11-32, 2019.

[12] W. Hao, Z. Zhang, Z. Gao, K. Yi, L. Liu, and J. Wang, "Research on mandatory lane-changing behavior in highway weaving sections," Journal of Advanced Transportation, vol. 2020, Article ID 3754062, 9 pages, 2020.

[13] K. Kim and B. J. Park, "Safety features of freeway weaving segments with a buffer-separated high-occupancy-vehicle (HOV) lane," International Journal of Injury Control and Safety Promotion, vol. 25, no. 3, pp. 284-292, 2018.

[14] Q. Cai, M. Saad, M. Abdel-Aty, J. Yuan, and J. Lee, "Safety impact of weaving distance on freeway facilities with managed lanes using both microscopic traffic and driving simulations," Transportation Research Record: Journal of the Transportation Research Board, vol. 2672, no. 39, pp. 130-141, 2018.

[15] B. Dong, X. Ma, F. Chen, and S. Chen, "Investigating the differences of single-vehicle and multivehicle accident probability using mixed logit model," Journal of Advanced Transportation, vol. 2018, Article ID 2702360, 9 pages, 2018.

[16] C. Liang, S. Cao, and Q. Tang, "Research on traffic characteristics of interchange area at ramp exit of urban expressway," Technology \& Economy in Areas of Communications, vol. 22 , no. 3, pp. 12-16, 2020.

[17] D. Lord and J. A. Bonneson, "Calibration of predictive models for estimating safety of ramp design configurations," Transportation Research Record Journal of the Transportation Research Board, vol. 1908, no. 1, pp. 88-95, 2005.

[18] A. Kusuma, R. Liu, C. Choudhury, and F. Montgomery, "Analysis of the driving behaviour at weaving section using multiple traffic surveillance data," Transportation Research Procedia, vol. 3, pp. 51-59, 2014.
[19] A. Kusuma, R. Liu, and C. Choudhury, "Modelling lanechanging mechanisms on motorway weaving sections," Transportmetrica B: Transport Dynamics, vol. 8, no. 1, pp. 121, 2020.

[20] J. Chi and Y. He, "Research on the safety evaluation method of weaving segments based on traffic conflict," Technology \& Economy in Areas of Communications, vol. 22, no. 4, pp. 27-32, 2020.

[21] X. Chen, L. Yu, L. Zhu, J. Guo, and M. Sun, "Microscopic traffic simulation aapproach to the capacity impact analysis of weaving sections for the exclusive bus lanes on an urban expressway," Journal of Transportation Engineering, vol. 136, no. 10, pp. 895-902, 2010.

[22] H. Rakha and Y. Zhang, "Analytical procedures for estimating capacity of freeway weaving, merge, and diverge sections," Journal of Transportation Engineering, vol. 132, no. 8, pp. $618-628,2006$.

[23] S. Tanaka, N. Hasegawa, D. Iizuka, and F. Nakamura, "Evaluation of vehicle control algorithm to avoid conflicts in weaving sections under fully-controlled condition in urban expressway," Transportation Research Procedia, vol. 21, pp. 199-207, 2017.

[24] Z. He, Analysis of Traffic Flow Characteristics in Multi-Lane Weaving Section of Urban Expressway, Hebei University of Technology, Tianjin, China, 2018.

[25] G. Tilg, K. Yang, and M. Menendez, "Evaluating the effects of automated vehicle technology on the capacity of freeway weaving sections," Transportation Research Part C: Emerging Technologies, vol. 96, pp. 3-21, 2018.

[26] X. Cai, S. Li, B. Peng et al., "Study on capacity model of weaving areas of arterial in mountainous city," in Proceedings of the 14th China Intelligent Transportation Annual Conference, the 14th China Intelligent Transportation Annual Conference, pp. 429-446, Qingdao, China, April 2019.

[27] Q. Ma, Y. Qiao, and M. Feng, "Traffic equilibrium organization method for neighbor weaving sections based on lanechanging constraints," Journal of Transportation Systems Engineering and Information Technology, vol. 4, pp. 164-171, 2019.

[28] J. Xie, B. Peng, X. Cai et al., "Research review on control strategy of urban expressway weaving area," Highways \& Automotive Applications, vol. 1, pp. 24-31, 2020.

[29] H. Li, Z. Huang, X. Zou, S. Zheng, and Y. Yeng, "VISSIMbased simulation and analysis of upstream segments in ramp areas for optimizing vehicle ggroup lane-changing behaviors," Journal of Advanced Transportation, vol. 2020, Article ID 5983161, 11 pages, 2020.

[30] M. Budzynski, K. Jamroz, W. Kustra, L. Michalski, and S. Gaca, "Road infrastructure safety management in Poland," IOP Conference Series: Materials Science and Engineering, vol. 245, 2017.

[31] Z. Wang, N. Guo, and J. Li, "Simulation to solve the reasonable length of weaving area of urban expressway," Journal of China \& Foreign Highway, vol. 27, no. 6, pp. 197-201, 2007.

[32] X. Chen, X. Xu, Y. Yang, H. Wu, J. Tang, and J. Zhao, "Augmented ship tracking under occlusion conditions from maritime surveillance videos," IEEE Access, vol. 8, pp. 42884-42897, 2020.

[33] X. Chen, Y. Yang, S. Wang et al., "Ship type recognition via a coarse-to-fine cascaded convolution neural network," Journal of Navigation, vol. 73, no. 4, pp. 813-832, 2020.

[34] X. Chen, S. Wang, C. Shi, H. Wu, J. Zhao, and J. Fu, "Robust ship tracking via multi-view learning and sparse representation," Journal of Navigation, vol. 72, no. 1, pp. 176-192, 2019. 
[35] JTG D20-2017, Highway Route Design Specification, 2017.

[36] T. Diao, Research on the Characteristics of Traffic Flow in the Weaving Area of Interchanges Based on Traffic Safety, Southeast University, Jiangsu, China, 2017.

[37] X. Zhang, Z. Guo, J. Gao, and R. Jiang, "Theoretical analysis on the safety of freeway entrance cconfluence area," Journal of Chongqing Jiaotong University, vol. 1, pp. 99-102, 2006.

[38] L. Kang and X. Huang, "Study on safety distance of urban expressway between the tunnel and grade separation," Traffic \& Transportation, vol. 35, no. 1, pp. 13-16, 2019. 